\title{
Summarizing the image adjectives for the construction of the picture database for lifestyle image board
}

\author{
Peng-Jyun Liu ${ }^{1,2, a}$ and Ming-Chuen Chuang ${ }^{1}$ \\ ${ }^{1}$ Institute of Applied Arts, National Chiao Tung University, Taiwan \\ ${ }^{2}$ Department of Creative Product Design, Asia University, Taiwan
}

\begin{abstract}
Design targets the promotion consumers' motivation to buy more products, whose sensual appeal has become the core of design. This research targets at the lifestyles of three major groups of people in Taiwan: "high-tech groups", "LOHAS groups", and "quality groups". Using literature review, questionnaires, and expert interviews, the frequently used images syntaxes used in three major dimensions: product design, designers, and lifestyle clusters are collected and summarized into 237 items. These image syntaxes are further categorized and selected, yielding 122 image syntaxes in six categories. At last, experts in different areas of design are requested to pick frequently used image syntaxes in the primary stage when designing for these three groups in order to construct the appropriate image syntaxes used in and their association with different areas of design and lifestyle clusters. The results can become the foundation of the next stage of this research in order to construct a lifestyle oriented image board database.
\end{abstract}

\section{Introduction}

Nowadays, consumers tend to buy merchandise with sensual appeal instead of functional purposes. Moreover, consumers are motivated to purchase merchandise that appeal to them sensually. In addition, the goal of design is to motivate consumers into consuming; therefore, the sensual appeal of products has become the core of design. In order to achieve this goal, designers introduce many different methods in the design process to inspire their design thinking. An image board is one of the methods frequently used by designers. According to related studies, consumers that have purchased products designed with image board show to have more pleasure and satisfaction from them [1]. Therefore, positive and active meanings in the overall design of products can be derived by introducing image board in the process of design. [2]

In the process of preparing and making image boards, the researchers encountered a few problems: 1. Most of the image graphics are collected in accordance with the designers' experience and personal feelings, showing to be subjective. 2. The association between image graphics and consumer groups are subjectively decided by the designers, and do not always comply with the intended objectives. 3 . Image graphics must be collected separately for each case, lowering efficiency. Moreover, graphics are mostly printed materials, occupying much space. And it is difficult to discard old materials to renew the archive. 4 . When engaging in interdisciplinary and joint design, it is difficult to integrate the

\footnotetext{
${ }^{\text {a }}$ Corresponding author : yu4038@asia.edu.tw
}

(C) The Authors, published by EDP Sciences. This is an open access article distributed under the terms of the Creative Commons Attribution License 4.0 (http://creativecommons.org/licenses/by/4.0/). 
image boards prepared by different teams, exerting certain difficulties in cooperation or participation in exhibition or development. 5. The appropriateness of the images or themes communicated through the graphics is not examined.

Considering the problems, this research proposes to construct lifestyle image boards from a broader perspective with Baxter's (1995) method[3] to construct a graphic database with images associated to different consumers' lifestyles to solve the problems of time and energy exhausting in collecting pictures, and avoid positioning the pictures and grouping them with the designers' subjective views. In this stage, this research plans to find out the image adjectives corresponding to different lifestyles.[4]

\section{Methodology}

In order to further understand the association between lifestyle and product category, literature review, questionnaire, and expert interview are used as method in this research. It intends to finish the lifestyle image syntaxes used frequently in three different lifestyle clusters and products.

First, the researchers determined the three major lifestyle clusters with reference to E-ICP Taiwan Lifestyle Bible, 2014, [5] a marketing database that analyzes Asian consumers. Then, online questionnaire was conducted to collect the image syntaxes frequently used in product design. The questionnaire was completed voluntarily by net users, with 26 valid questionnaires. The age group falling between 19 and 30, 17 of them were working people, and 9 students. 12 of them had a design background, and 14 of them had no design background. Moreover, massive image syntaxes used frequently by designers were collected by reviewing related literature, newspaper, magazines, and more. Then, five professional designers with at least five years of experience in related fields were invited to attend the expert interview. They were requested to identify the syntaxes used frequently in design from the pool. At the same time, this research also collected and categorized image syntaxes related to three major lifestyles by reviewing related literature, newspapers, and magazines.

This research integrated the images syntaxes collected from three perspectives. Then five experts with at least five years of experience in design were invited to a focus group interview to categorize and delete the image syntaxes. The experts included four males and one female (as shown in Fig. 4), with ages between 30 and 50 years old. Two of them were design teachers in universities, and the other two were experts in the field of design. The last one was marketing expert, who contributed to point out the consumers' perspectives, with no design background.

The categorization of image syntaxes was conducted in three stages. In stage one, flash cards were made with all the integrated image syntaxes. They were categorized by experts with consensus derived from discussions in accordance with the similarities of the semantic meanings of the syntaxes. In stage two, the image syntaxes were further integrated in accordance with the similarities of images and the habitual similarities of the designers" applications. In stage three, image naming was conducted with the materials categorized in stage two. In order to condense the large number of images derived after integration, the same group of experts was requested to choose the most appropriate syntax from each group of syntaxes.

This research invited six designers in different fields, including kitchenware, furniture, transportation, communication, and industrial machinery, to help fine-tune these syntaxes for convenient applicability in the designs of different products. These designers fell into the age group between 32 and 50, with at least 6 years of experience in design. During individual interviews, they were requested to pick the adjectives used in their areas and image syntaxes applicable in product design for the three major lifestyle clusters. During the interview, the features and pictures related to the three lifestyle clusters were introduced and provided for the designers' references. Then, the interviewees were requested to select the most frequently used image syntaxes in the three major lifestyle clusters.

\section{Results and discussion}




\subsection{Investigation of lifestyle cluster}

This research focus on the investigation of lifestyle clusters in Taiwan. At present, the database E-ICP Taiwan Lifestyle Bible (2014) constructed by Eastern Online Co Ltd provides very complete references to the lifestyle clusters and consumer behaviors in Taiwan. Therefore, this research consulted the databank and regarded the ten major lifestyle clusters as the sources of this project. From these ten lifestyle clusters, the research team has chosen three identifiable clusters with potential consuming ability as the targets. They is the "high-tech lifestyle cluster," "LOHAS lifestyle cluster," and "quality living lifestyle cluster," whose features are illustrated in Table 1:

Table 1. Ten major lifestyle clusters in Taiwan as shown in E-ICP 2014.

\begin{tabular}{|c|l|}
\hline Lifestyle cluster & Personalities and features \\
\hline High-tech lifestyle & Science and tech pro, high-tech lifestyle, innovative, anti-high-tech \\
\hline LOHAS lifestyle & Self-regulated, self-complacent, indulging, wanderer, otaku \\
\hline Quality living lifestyle & $\begin{array}{l}\text { Active and adventurous, eager and enthusiastic, enjoy life, secluded and otaku, firm } \\
\text { and steady }\end{array}$ \\
\hline
\end{tabular}

Remarks: The research design and statistics method of this table are results of the collaboration between Eastern Online and the Institute of Business Administration, NCCU.

\subsection{Collection of adjectives}

The adjectives were collected from three perspectives, including the adjectives used on wrappings, the adjective collections used frequently by designers, and adjectives of different lifestyle clusters.

\subsubsection{Collection of adjectives used frequently on product design}

Online questionnaire was conducted to collect the image syntaxes frequently used on product design. The questionnaire was conducted at random, opened to net users via the internet. The testees were requested to fill out the adjectives used frequently in design. The totals of 27 questionnaires were sent out, with 1 invalid questionnaire and 27 valid ones. Falling between the age of 19 and 45, 14 of the testees were working people, and nine of them were students. Eight of them were males, and 19 females, with 12 of them had backgrounds in design, and 14 of them had no design background. The total number of adjectives collected was 160, 31 of them had repeated twice or more. Nine of the testees expressed that they often used the term "practical;" six suggested the term "simple"; and five raised the term "handy." For the other repetitions, please consult Table 2. In Table 1, the figures listed behind the adjectives were the numbers of testees that used the terms frequents. For example, the number (9) means that nine of the testees use the term frequently.

Table 2. Results of the online investigation of the image syntaxes used frequently in design.

\begin{tabular}{|c|c|c|c|c|c|}
\hline Practical (9) & Safe(4) & Streamlined(3 & Humanistic(2) & Good-looking (2) & Chic (2) \\
\hline Simple(6) & Magnificent(3) & Simplistic (3) & Refined (2) & Complicated (2) & Interesting (2) \\
\hline Handy(5) & Durable (3) & Abstract (2) & Organic (2) & Fashionable (2) & Colorful (2) \\
\hline Neat(4) & Creative(3) & Multifunctional (2) & Generous (2) & Pretty (2) & Amiable (2) \\
\hline Luxurious(4) & Convenient (3) & Bright (2) & Cute (2) & Concise (2) & Amazing (2) \\
\hline Hi-tech(4) & & & & & \\
\hline
\end{tabular}

\subsubsection{Collection of adjectives used frequently by designers}

From related literature [6-11], newspapers, magazines, and more, 188 adjectives used frequently by designers were collected. After reviewing, they were summarized into 144. Five experts were invited 
to choose the image syntaxes used frequently by them. Two or more of them picked 34 frequently used image syntaxes, as shown in Table 3.

Table 3. Collections of adjectives used frequently by designers.

\begin{tabular}{|c|c|c|c|c|c|}
\hline Classical & Harmonious & Clean & Neat & Vintage & Light \\
\hline Leisurely & Bright & Fast & Elegant & Magnificent & Sensual \\
\hline Lively & Convenient & Quiet & Stable & Refined & Symmetric \\
\hline High-tech & Avant-garde & Comfortable & Natural & Cute & Proportional \\
\hline Character & Gentle & Manly & Cool & Stylish & Cozy \\
\hline Romantic & Soft & Traditional & Classy & & \\
\hline
\end{tabular}

\subsubsection{Collection of adjectives used by lifestyle clusters}

From related literature [12,5], newspaper, magazines, and more, 148 image syntaxes used by LOHAS lifestyle clusters were collected. After revision, there were 60 adjectives. From the high-tech lifestyle clusters, 81 image syntaxes were collected. After revision, there were 51 adjectives. From the quality living lifestyle cluster, 108 image syntaxes were collected. After revision, there were 78 adjectives.

\subsubsection{Categorization of the adjectives}

254 image syntaxes from the three perspectives mentioned above were collected. Deleting the repeats, 234 were derived, and they were further categorized by experts. In stage one, the experts divided the 234 image syntaxes into 15 categories. In stage two, the experts condensed the 15 categories into 6 types. In stage three, these six categories were named, "image of everyday life" with 41 image syntaxes; "traditional image, 21 syntax images", "image of style," 15; "image of luxury," 55; "image of sustaining," 26; and "image of high-tech," 76.

Then, the experts selected the most frequently used images from the above and yielded 21 images of everyday life, 12 images of tradition, 12 images of style, 32 images of luxury, 16 images of sustaining, and 29 images of high-tech with the total of 122, as shown in Table4. Image syntax (2) implies the syntaxes selected by two or more experts(table 4 ).

Table 4. Image syntaxes (after abbreviating).

\begin{tabular}{|c|l|}
\hline Image categories & \multicolumn{1}{c|}{ Adjectives } \\
\hline Images of everyday life & $\begin{array}{l}\text { Life (5), home (5), cozy (4), fresh (3), relaxing (3), stress-free (3), humanistic (2), } \\
\text { leisure (2), safe (2), free (2), harmonious (2), warm (2), tranquil (2), hospitable (2), } \\
\text { simple, plain, clean, elegant, pleasing, comfortable, light }\end{array}$ \\
\hline Images of tradition & $\begin{array}{l}\text { Cultural (5), traditional (5), reserved (3), silent (3), typical (3), conservative (3), } \\
\text { solemn (2), well-behaved (2), vintage (2), rustic (3), sincere, careful }\end{array}$ \\
\hline Images of style & $\begin{array}{l}\text { Ultra-simplistic (4), streamlined (4), classical (3), geometrical (3), neat (3), organic } \\
\text { (3), three-dimensional (2), smooth (2), simplistic (2), simple, heavy, soft }\end{array}$ \\
\hline Images of luxury & $\begin{array}{l}\text { Refined (5), lofty (4), quality (4), luxurious (4), brand-name (3), classy (3), high- } \\
\text { class (3), chic (3), deluxe (3), magnificent (3), pricy (2), material (2), eye-catching } \\
\text { (2), good taste (2), gorgeous (2), fashionable (2), charming (2), complicated (2), } \\
\text { vivid, artistic, aesthetics, graceful, aesthetics, modern, delicate, visual, sensual, } \\
\text { meticulous, quality, fancy, romantic, bright }\end{array}$ \\
\hline Images of sustaining & $\begin{array}{l}\text { Sustaining (5), environmental friend (5), natural (4), ecological (4), healthy (4), } \\
\text { energy saving (3), natural (3), valuable (3), handy (2), generic (2), convenient, } \\
\text { durable, sturdy, manageable, practical, hand-made }\end{array}$ \\
\hline Images of high-tech & $\begin{array}{l}\text { Digital (4), efficiency (4), avant-garde (3), efficient (3), intelligent (3), professional } \\
\text { (3), hard (3), high-tech (3), rational (3), designed (3), future (2), multifunctional } \\
\text { (2), popular (2), accurate (2), fashionable (2), intelligent (2), creative (2), } \\
\text { innovative (2), novel (2), pioneer (3), unique(2), Synthetic, cold, urban, special, } \\
\text { urban, effective, prompt, systematic, conceptual }\end{array}$ \\
\hline
\end{tabular}




\subsection{Integration of image syntaxes used by different lifestyle clusters and in different areas of design}

\subsubsection{Investigation results of applications of image syntaxes used in different areas of design}

Designers from different areas picked the most frequently used images syntaxes from 122 items, listed above, applicable in three different lifestyle clusters - the high-tech lifestyle cluster, LOHAS lifestyle cluster, and quality living lifestyle cluster, as listed in Table 5

Table 5. Image syntaxes frequently used by designers in different areas of design.

\begin{tabular}{|c|c|c|c|c|c|c|c|c|}
\hline \multicolumn{2}{|c|}{$\begin{array}{c}\text { Area } \\
\text { Category }\end{array}$} & Kitchenware & Furniture & Vehicles & \begin{tabular}{|l|} 
Computer \\
appliances
\end{tabular} & $\begin{array}{c}\text { Communication } \\
\text { equipment }\end{array}$ & Machinery & \begin{tabular}{|c} 
Repetition \\
rate
\end{tabular} \\
\hline \multirow{4}{*}{$\begin{array}{l}\text { Everyday } \\
\text { life }\end{array}$} & Humanistic & (C) & (C) & & (C) & () & (0) & 83 \\
\hline & Pleasing & (C) & (C) & (C) & (C) & & & 67 \\
\hline & Neat & & & & (a) & (C) & (C) & 50 \\
\hline & n....... & & & & & & & \\
\hline \multirow{4}{*}{ Tradition } & Restrained & (2) & & (C) & (a) & & (C) & 67 \\
\hline & Cultural & & (C) & (2) & (C) & & (2) & 67 \\
\hline & \begin{tabular}{|l|} 
Typical \\
\end{tabular} & () & (C) & & (2) & & (C) & 67 \\
\hline & & & & & & & & \\
\hline \multirow{4}{*}{ Style } & Classical & (2) & & (C) & $(0)$ & & & 50 \\
\hline & \begin{tabular}{|l|} 
Three- \\
dimensional
\end{tabular} & & & (2) & (C) & & & 33 \\
\hline & Organic & (C) & & (C) & (C) & & & 50 \\
\hline & & & & & & & & \\
\hline \multirow{4}{*}{ Luxurious } & Expensive & & (C) & (C) & (C) & (C) & & 67 \\
\hline & Quality & & (C) & (C) & (C) & & & 50 \\
\hline & Brand name & (2) & (2) & (2) & $(0)$ & & (2) & 50 \\
\hline & ............ & & & & & & & \\
\hline \multirow{4}{*}{ Sustaining } & Natural & & (C) & (C) & (2) & (C) & (2) & 83 \\
\hline & Hand-made & & & & (C) & & & 17 \\
\hline & Sustaining & & (C) & (C) & (C) & & & 50 \\
\hline & …......... & & & & & & & \\
\hline \multirow{4}{*}{ High-tech } & Artificial & & & & & & & 0 \\
\hline & \begin{tabular}{|l|} 
Future \\
\end{tabular} & & (2) & (C) & (2) & (C) & & 67 \\
\hline & Conceptual & & (C) & & (C) & & & 33 \\
\hline & $\begin{array}{l}\ldots \ldots \ldots \ldots \\
\end{array}$ & & & & & & & \\
\hline
\end{tabular}

\subsubsection{Investigation results of applications of image syntaxes used in the lifestyle clusters}

The designers in different areas were requested to choose the image syntaxes used in different lifestyle clusters to obtain more accurate image syntaxes. The image syntaxes without targeting at any specific realm used by the designers in different areas were analyzed. The survey found that as shown in table 6.

According to Table 6, when constructing the construction of databank, the image syntaxes are arranged with the following guidelines:

- Level 1: Used frequently by designers in various fields.

- Level 2: Used frequently by designers in various fields and sometimes by three lifestyle clusters.

- Level 3: Used by both designers in various fields and three lifestyle clusters.

- Level 4: Area-dependent in each lifestyle cluster. 
Table 6. Investigation of the image syntaxes used in the lifestyle clusters of luxury, sustaining, and high-tech.

\begin{tabular}{|c|c|c|c|}
\hline Category & Design Category & Classification & Images of vocabulary \\
\hline \multirow{12}{*}{ Life Images } & \multirow[t]{2}{*}{ Kitchen supplies } & Both & $\begin{array}{l}\text { Humanity 、 Pleasure Comfortable } 、 \text { Life } \\
\text { Relaxation 、 Comfortable }\end{array}$ \\
\hline & & 3 ethnic groups have & Humanity \\
\hline & \multirow[t]{2}{*}{ Furniture Design } & Both & $\begin{array}{c}\text { Humanity } 、 \text { Pleasure } 、 \text { Comfortable } \\
\text { Harmony }\end{array}$ \\
\hline & & 3 ethnic groups have & Humanity \\
\hline & \multirow{2}{*}{$\begin{array}{l}\text { means of transport } \\
\text { Design }\end{array}$} & Both & $\begin{array}{c}\text { Pleasure } 、 \text { Easy } 、 \text { Comfortable } 、 \text { Life } 、 \\
\text { Warm } 、 \text { Harmony }\end{array}$ \\
\hline & & 3 ethnic groups have & Harmony \\
\hline & \multirow[t]{2}{*}{ Computer Equipment } & Both & $\begin{array}{c}\text { Humanity 、 Friendly 、 Pleasure 、 } \\
\text { Austere } \text {. Easy 、 Homely 、 Life 、 } \\
\text { Warm 、 Refreshing } \text { Harmony } 、 \text { Leisure 、 } \\
\text { Plain }\end{array}$ \\
\hline & & 3 ethnic groups have & Humanity $、$ Life \\
\hline & \multirow{2}{*}{$\begin{array}{c}\text { Communications } \\
\text { equipment }\end{array}$} & Both & Humanity \\
\hline & & 3 ethnic groups have & \\
\hline & \multirow{2}{*}{$\begin{array}{l}\text { Industrial machinery } \\
\text { and equipment }\end{array}$} & Both & $\begin{array}{c}\text { Humanity } 、 \text { Friendly } 、 \text { Austere } 、 \text { Easy } \\
\text { Security } 、 \text { Plain }\end{array}$ \\
\hline & & 3 ethnic groups have & Humanity \\
\hline \multirow{2}{*}{$\begin{array}{l}\text { Traditional } \\
\text { Images }\end{array}$} & \multirow{2}{*}{ Kitchen supplies } & Both & Introverted 、 Quiet 、 Rules \\
\hline & & 3 ethnic groups have & n........ \\
\hline
\end{tabular}

Source: This study investigated

Therefore, in this study the vocabulary of Images of extraction results shown in Table 7. The Construction database for design use, therefore, in order to extract Images of vocabulary designers use on all areas across two levels as the main basis for selection and coupled with individual lifestyle ethnic specificity Images of vocabulary. Overall, Life Images have 8 Images of vocabulary; Traditional Images have 6 Images of vocabulary; Style Images have 5 Images of vocabulary; Luxury Images have 11 Images of vocabulary; Technology Images have 12 Images of vocabulary. These images will be used as the second phase of stimulus vocabulary sample image of keyword selection. Therefore the image syntaxes summarized by this research are listed in Table 7.

Table 7. The image syntaxes summarized by this research are listed.

\begin{tabular}{|c|c|c|c|c|c|c|}
\hline Level & $\begin{array}{c}\text { Image of } \\
\text { everyday life }\end{array}$ & $\begin{array}{c}\text { Image of } \\
\text { tradition }\end{array}$ & Image of style & $\begin{array}{c}\text { Image of } \\
\text { luxury }\end{array}$ & $\begin{array}{c}\text { Image of } \\
\text { sustaining }\end{array}$ & $\begin{array}{c}\text { Image of } \\
\text { high-tech }\end{array}$ \\
\hline \multirow{6}{*}{1} & Humanistic & Restrained & Classical & Expensive & Natural & Future \\
& Pleasing & Cultural & Organic & Quality & Sustaining & Multi- \\
& Simple & Typical & Soft & Good taste & Ecological & functional \\
& Casual & Well- & Smooth & Brand name & Ease & Systematic \\
& Comfortable & behaved & Streamlined & Fashionable & Durable & Accurate \\
& Home & Vintage & Ultra-simplistic & High-class & Healthy & Hi-tech \\
& Safe & Traditional & Concise & Elegant & Energy saving & Efficiency \\
& Everyday life & & Simple & Extravagant & Practical & Special \\
& Harmonious & & Neat & & Environmental & Hi- \\
& & & & & friendly & intelligent \\
& & & & & & Professional \\
& & & & & & Design \\
& & & & & & \\
\end{tabular}




\begin{tabular}{|c|c|c|c|c|c|c|}
\hline 2 & $\begin{array}{l}\text { Humanistic } \\
\text { Pleasing } \\
\text { Comfortable } \\
\text { Everyday life }\end{array}$ & $\begin{array}{c}\text { Restrained } \\
\text { Typical } \\
\text { Vintage } \\
\text { Rustic }\end{array}$ & $\begin{array}{c}\text { Streamlined } \\
\text { Ultra-simplistic } \\
\text { Neat } \\
\text { Simple }\end{array}$ & $\begin{array}{l}\text { Brand name } \\
\text { Good taste } \\
\text { Fashionable } \\
\text { Quality } \\
\text { Expensive } \\
\text { Quality }\end{array}$ & $\begin{array}{c}\text { Healthy } \\
\text { Natural } \\
\text { Sustaining } \\
\text { Ecological } \\
\text { Ease } \\
\text { Energy saving } \\
\text { Practical } \\
\text { Environmental } \\
\text { friendly }\end{array}$ & $\begin{array}{c}\text { Hi-tech } \\
\text { Efficiency } \\
\text { Efficacy } \\
\text { Hi- } \\
\text { intelligent } \\
\text { Professional } \\
\text { Design } \\
\text { Innovative } \\
\text { Future } \\
\text { Digital } \\
\text { Conceptual }\end{array}$ \\
\hline 3 & $\begin{array}{l}\text { Humanistic } \\
\text { Harmonious } \\
\text { Everyday life }\end{array}$ & $\begin{array}{c}\text { Vintage } \\
\text { Restrained } \\
\text { Cultural } \\
\text { Rustic }\end{array}$ & $\begin{array}{c}\text { Neat } \\
\text { Three- } \\
\text { dimensional } \\
\text { Simple }\end{array}$ & $\begin{array}{c}\text { Expensive } \\
\text { Good taste } \\
\text { Fashionable } \\
\text { Quality } \\
\text { Artistic } \\
\text { High-class } \\
\text { Fine }\end{array}$ & $\begin{array}{l}\text { Natural } \\
\text { Ecological } \\
\text { Generic }\end{array}$ & $\begin{array}{c}\text { Hi- } \\
\text { intelligent } \\
\text { Future } \\
\text { Effective } \\
\text { Accurate } \\
\text { Urban } \\
\text { Creative } \\
\text { Innovative }\end{array}$ \\
\hline 4 & $\begin{array}{l}\text { Unrestrained } \\
\text { Clean } \\
\text { Graceful } \\
\text { Warm }\end{array}$ & Careful & & $\begin{array}{c}\text { Fashionable } \\
\text { Charming } \\
\text { Refined } \\
\text { Complicated } \\
\text { Romantic } \\
\end{array}$ & $\begin{array}{c}\text { Handy } \\
\text { Hand-made } \\
\text { Value }\end{array}$ & $\begin{array}{c}\text { Cold } \\
\text { Avant-garde } \\
\text { Popular }\end{array}$ \\
\hline
\end{tabular}

This research had collected 237 image syntaxes from three lifestyle clusters: the "high-tech cluster," "LOHAS cluster," and "quality living cluster," which are used frequently in product designs by designers and lifestyle clusters, through a literature review, questionnaire, and expert interview as its research method. Then focus group interviews with experts were conducted to select and categorize these syntaxes further to yield 122 image syntaxes in six categories. At last, experts in different fields picked the most frequently used image syntaxes from these 122 images to derive adjectives applicable in the three major lifestyle clusters to construct the relationships between different areas of design, different lifestyle clusters, and image syntaxes. The research results will be used in the studies in the next stage to construct the foundation lifestyle oriented image board database.

This research discovered that there is no significant different regarding the designers' cognition of the applicability of the image syntaxes in these three lifestyle clusters. It will be helpful in the collection of graphics, positioning, and grouping in the next stage. Eventually, there are still quite a number of terms derived from the shrinking of the 122 image syntaxes in three stages. These image syntaxes will be further selected in the next stage by the people in the three mentioned lifestyle clusters upon request to render these image syntaxes closer to the everyday life needs in each cluster.

\section{References}

1. M.W. Brown, The teacher-tool relationship: Theorizing the design and use of curriculum materials, Connecting curriculum materials and classroom instruction, 17-36 (New York, 2009)

2. P.J. Yi and Y.M. Zhang, A study of the process of mature period product differentiation-The proposal of multi-image features deduction method, Kung University master's thesis (2006)

3. M. Baxter, Product design, practical methods for systematic development of new products, Chapman \& Hall (London, 1995)

4. G.A. Kelly, The psychology of personal constructs (New York, 1995)

5. Taiwan Lifestyle Bible, Eastern online (Taipei, Taiwan, 2014) 
6. R.C. Chou, Create complex perceptual Image - to shape features based, Cheng Kung University Thesis (2000)

7. H.W. Lin, Research Product Images search mechanism used in the Internet, Cheng Kung University Thesis (2000)

8. M.C. Chuang and C.C. Chen, Journal of Design, 9(3), 43-58 (2004)

9. Y.Y Chan, Studies hair like the imagery used in product shape-picture to picture motion imagery, for example, should be surgery, Chiao Tung University Institute of Thesis (2005)

10. S.H. Hung and M.C. Chuang, Taiwan Textile Research Journal, 18(3), 42-52 (2008)

11. Y.R. Chun and Y.J. Ya, To investigate the behavior of daily life information from LOHAS lifestyle of view, Shih Hsin University Thesis (2007)

12. R.Y. Lee, The study of consumer goods consumers of cultural and creative motivation, lifestyle and consumer behavior of the Di Ye University Thesis (2013) 